\title{
Variation of Pressure Coefficient Along Bottom of Dam Vertical Lift Gates
}

\author{
Thamir M. Ahmed ${ }^{1}$
}

Received: 13 July 2018/ Accepted: 19 March 2020/Published online: 30 March 2020

(C) The Institution of Engineers (India) 2020

\begin{abstract}
The vertical lift gates are exposed to hydrodynamic forces that arise as a result of pressurized flow established by the large-scale effect of the water levels in the dam reservoirs. The most influential forces are those that are applied on the gate vertically upward due to the intensity of the flow under the gate and downward as a result of passage flow above the gate. The difference between these two forces generates a downpull force that is the most important gate stability indicator. In this research, an arbitrary hydraulic model was constructed to investigate the effects of many gate lip shapes with and without extensions on the magnitudes and distribution of bottom pressure coefficient when the values of flow and shaft gap width ratio $\left(b_{2} / b_{1}\right)$ are constant. The results indicate that the bottom pressure coefficient appears to vary uniformly with gate openings and seem to be influenced effectively by the gate lip geometry. So, for the given value of $\left(b_{2} / b_{1}\right)$, the top pressure coefficient regarding the downward force will mostly be with uniform changes and hence the downpull coefficient depends on the magnitudes and distribution of bottom pressure coefficient. An attempt by using the correlation coefficient of Statistical Package of Social Sciences was made to determine whether the pressure fluctuation is significantly shown at the bottom pressure distribution curve, which in turn is considered as appropriate indicator for the vibration occurrence. Full range of maximum bottom pressure coefficients in a matrix form is made to assist in design purposes. The results are analyzed and many conclusions are obtained.
\end{abstract}

Thamir M. Ahmed

thamir.ahmed@tiu.edu.iq

Civil Engineering Department, Tishk University, Arbīl, Iraq
Keywords Hydrodynamic forces - Vertical lift gate · Pressure coefficient

\section{List of Symbols}

$A \quad$ Appropriate cross-sectional area of the tunnel $\left(\mathrm{m}^{2}\right)$

$B \quad$ Tunnel width (m)

$b_{1}, b_{2} \quad \mathrm{U} / \mathrm{S}$ and $\mathrm{D} / \mathrm{S}$ gap widths between the gate and the gate shaft

$d \quad$ Gate thickness (m)

$F_{\text {d }} \quad$ Downpull force $(\mathrm{N})$

$g \quad$ Gravity acceleration $\left(\mathrm{m}^{2} / \mathrm{s}\right)$

$H_{i} \quad$ Pressure head at a point on the gate bottom (m)

$H_{\mathrm{t}} \quad$ Pressure head on the top surface of the gate (m)

$H_{\mathrm{U}} \quad$ Pressure head U/S of the gate (m)

$H_{\mathrm{d}} \quad$ Pressure head D/S of the gate (m)

$K_{\mathrm{b}} \quad$ Bottom pressure coefficient (dimensionless)

$K_{\mathrm{d}} \quad$ Downpull coefficient (dimensionless)

$K_{\mathrm{t}} \quad$ Top pressure coefficient (dimensionless)

$P \quad$ Perimeter of tunnel section (m)

$Q \quad$ Total rate of flow $\left(\mathrm{m}^{3} / \mathrm{s}\right)$

Re Reynolds number (dimensionless)

$V \quad$ Average velocity $(\mathrm{m} / \mathrm{s})$

$V_{\mathrm{j}} \quad$ Velocity in the contracted jet issuing from under beneath the gate $(\mathrm{m} / \mathrm{s})$

$X \quad$ The horizontal distance from the leading edge of gate lip toward trailing edge $(\mathrm{m})$

$Y \quad$ Height of gate opening (m)

$Y_{o} \quad$ Tunnel height (m)

v Kinematic viscosity $\left(\mathrm{m}^{2} / \mathrm{s}\right)$

$\theta \quad$ Angle between horizontal and sloping bottom of the gate (degree)

$\rho \quad$ Density of water $\left(\mathrm{kg} / \mathrm{m}^{3}\right)$

$\gamma \quad$ Specific weight of water $\left(\mathrm{N} / \mathrm{m}^{3}\right)$ 


\section{Introduction}

The stability of vertical lift gates is based mainly on the downpull force which is resulted from the difference between the downward force of flow passing through the gate shaft and the upward force induced by jet flow on the bottom gate surface. In the case of a slight change in top pressure coefficient, the downpull force will be significantly affected by bottom pressure coefficient. The vertical lift gates are seen to be subjected to serious challenges due to the vibration caused by the pressure fluctuation below the gate bottom surface which requires serious consideration in design, Bhargava [3]. A variety of factors that clearly affect the pressure coefficients can be classified into three groups, the flow characteristics involving the operating head on the gate, the liquid properties and geometrical features. Although these factors are not on the same degree of influence, they act in an integrated manner, Sagar [8]. All these factors have been taken into account to assess their effect on the hydraulic forces that are formed on the gates by pressurized flow. Nudashcher [5] and others conducted regular air tunnel experiments to assess the effects of flow parameters and boundary geometry on the downpull forces exerted on high vertical leaf gates. The study concluded that a one-dimensional format can be used to estimate the downpull force based upon the determination of local piezometric heads on bottom gate surface in addition to the jet velocity heads and piezometric head just downstream the gate shaft. Elder [4] presented the results of experimental study of simulating 3-leafintake in Milton Hill Dam. Tests had examined the oscillation and leaf close failure on five proposed lip gate shapes and on other nine basic forms. The tests revealed some difficulties due to the large hydraulic forces caused by the shapes of lips. The study concluded that the new form of gate resulting from lip combination leads to acceptable design. The US Bureau of Reclamation and Army Engineers [12] conducted many experiments and found that downpull can be expressed in terms of upstream head:

$F_{\mathrm{d}}=\gamma \cdot K_{\mathrm{d}} \cdot H \cdot A$.

Sagar [9] reported the numerous geometrical features of the gate influencing the downpull, which can be formulated as follows:

$F_{\mathrm{d}}=\left(\mathrm{Hu}, \frac{Y}{Y_{\mathrm{o}}}, \frac{e}{d}, \theta, \frac{b_{1}}{b_{2}}, \frac{d}{Y_{\mathrm{o}}}, \frac{r}{d}\right)$

Two experimental methods for evaluating the bottom force were proposed by Sagar [9], the downpull coefficient method based on the Fort Randall dam data and the pressure distribution method based on an estimate of the total forces operating on the upper and lower surfaces of a gate. These two experimental methods were restricted and can be applied only to shapes which are similar to those used in the development of formulas.

Smith [10] has studied downpull force on a high-head leaf gate using different gate lip shapes, gate closing speed, and discharge ratings. The study concluded that the maximum downpull on the movable gate during closure was only $74 \%$ of that on the gate in fixed slots. The study shows that the hydrodynamic force on the gate is a function of the Froude number, gate opening, and geometry of gate lip.

Nguyen [6] studied the effects of different flow conditions on the high local pressures and the discharge characteristics of the vertical lift gates. The characteristics of the disturbance conditions near the separation point from the bottom of the gate were indicated by using the Doppler laser, and the measurement of the intensity of the nose was shown. The study concluded that the variations of the downpull and flow coefficients are influenced by the sensitivity of the separated flow pattern near the gate surface which caused turbulent current and changes in flow rate. The separation of the flow from the bottom gate surface is shown to produce adverse effects on the downpull coefficient compared to the free form disturbance.

Bhargava [3] investigated the pressure fluctuations on various geometries of vertical lift gates. In the variation of the distribution pattern, the spatial correlations and the intensity of the pressure fluctuations were studied when the gate had to vibrate in the vertical direction at specified frequencies and amplitude. The total pressure intensity of the gates was obtained by vibrating the gate, and the study shows the dominant frequency pressure which can be presented as critical condition for the design of hydraulic lift gates.

Nguyen [7] studied the influence of unstable loads on behavior of vertical lifting gates with different geometrical gate lip shapes and discharge conditions in an open channel. Vibrations occurred in specific ranges of a non-dimensional parameters of velocity as the flow fluctuated between attachment and reattachment at the bottom of the gate. The excitation mechanism is attributed to the combined effect of the instability in the shear layer and the induced impulses that fall at the front edge of the gate. It has been shown that the slope of the average lift curve running on the bottom of the gate provides an effective way to precisely predict critical scale of the gate openings with respect to the potential gate vibration.

Al-Kadi [2] provided a one-dimensional mathematical model to analyze the effect of discharge on effective piezometric heads at the top and bottom surfaces of the gate, in addition to the prediction of the flow state downstream the gate shaft. The analyses are verified by comparing the results with the observed measurement. The forces of downpull action on the bottom were estimated by predicting average pressure and velocity distribution using 
two models of finite elements, one with a fixed vortex viscosity and the other with a variable vortex viscosity which is important in determining the negative downward pull of large gates. The model is verified using analytical prediction and gives a good agreement.

In the current study, the bottom pressure coefficients $\left(K_{\mathrm{b}}\right)$ on the gates are evaluated for different gate lip geometries and gate openings. The measurements are taken by using the hydraulic of tunnel model with six different lip shapes. An attempt by using the correlation coefficient of Statistical Package of Social Sciences (SPSS) was made to determine whether the fluctuation does occur in the bottom pressure distribution curve. This correlation coefficient is considered as an appropriate indicator for the vibration occurrence due to the phenomenon of attachment and reattachment of flow on the gate bottom surface. Although this method will not achieve a high level of accuracy, it remains important to indicate the general context of the pressure along the bottom gate surface for different gate shapes and openings. All results are analyzed and many conclusions are attained.

\section{Experimental Setup}

The experiments were conducted on a rectangular glasswalled recirculating flume, $4 \mathrm{~m}$ long, $0.2 \mathrm{~m}$ wide, and $0.3 \mathrm{~m}$ deep with horizontal steel floor. To change the open channel into a tunnel, a metal plate was placed tightly along the top of the channel. The gate shaft $(0.3 \times 0.15 \times 0.9) \mathrm{m}$ was installed mid-way along the tunnel. It was made by steel (channel shape) and covered by the plate. The downstream end of the flume was provided by a gate to control the tunnel flow conditions as needed. A/C motor was used to derive a $3.75-\mathrm{kw}$ pump; thus, the required discharge was adjusted by a valve provided to the inlet of tunnel. The tunnel was fed by a stilling tank designed to produce flow condition free, to

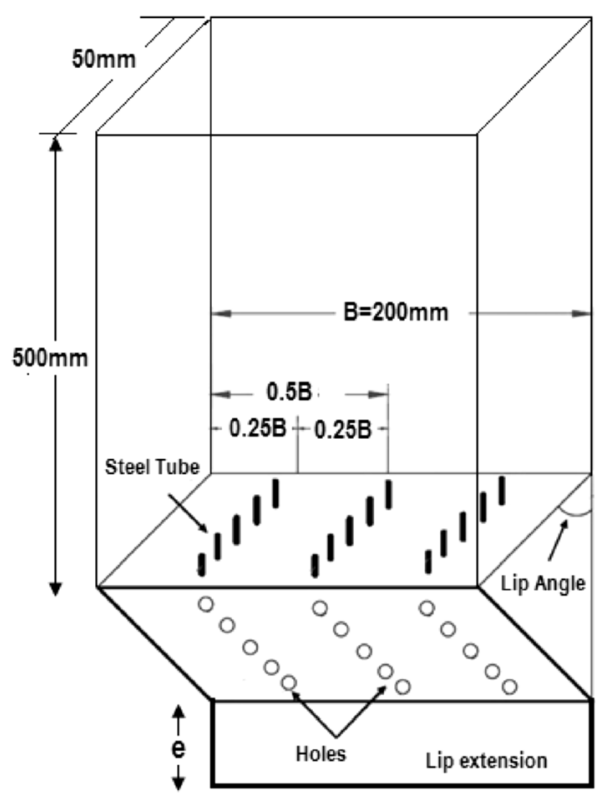

Fig. 2 Gate model

acceptable limit, from turbulence effects. A schematic layout of the tunnel is shown in Fig. 1. The gate model is made by a thick plate with a thickness of $50 \mathrm{~mm}$ supported by a steel frame and connected to the top of the shaft to adjust the vertical movement of the gate to the required openings. The six interchangeable bottom gate lips of the steel block have been formed as (three shapes without extension and the others with extension for different ratios to gate thickness), each fitted with two sets of taps, $4 \mathrm{~mm}$ diameter, located along the lip parallel to the flow direction; the first set with five taps fixed at a distance of $0.25 \mathrm{~B}$ from the right edge of the gate with an equal parting distance, and the second set of five taps were located by the same manner at center line of gate bottom surface. Short steel tubes were inserted into taps to facilitate their connection through the plastic tubes to the piezometers board. The main components of gate lip are
Fig. 1 Scheme of hydraulic model

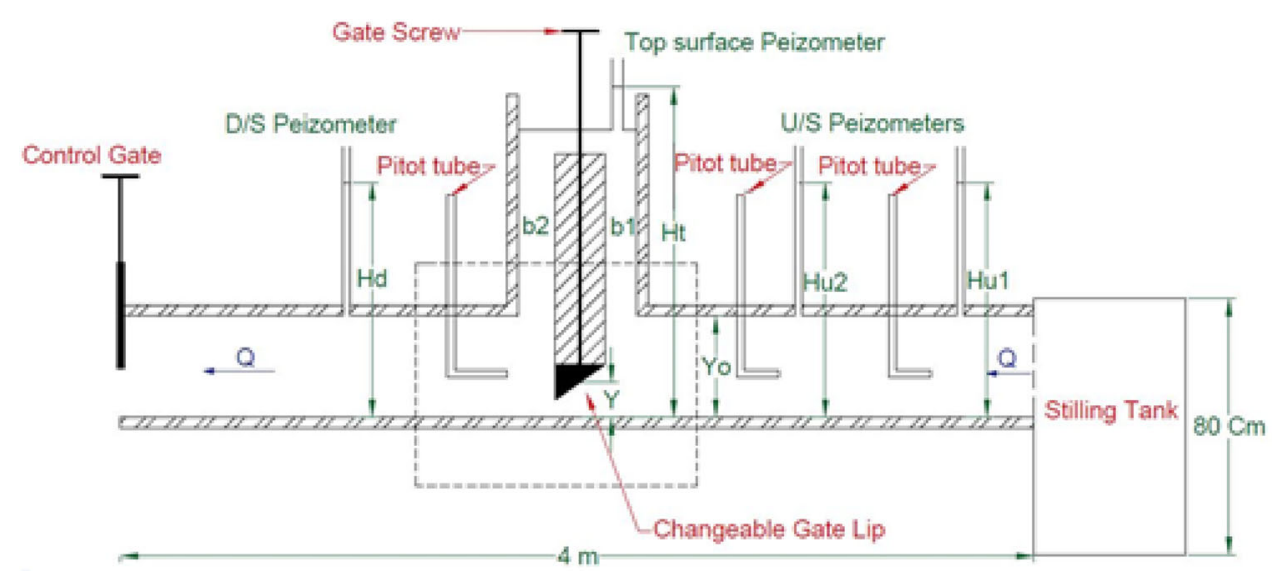


shown in Fig. 2, and the gate lip shapes considered for the current study are located next to the corresponding figures of results.

\section{Distribution of Bottom Pressure Coefficient $\left(K_{b}\right)$}

As the pressure along the gate top surface is mostly invariant and approaches the state of regularity, the bottom pressure generated by the issuing flow below the gate will have the greatest impact on the hydrodynamic forces and consequently on the operational performance of the gate. Therefore, the study of the factors that affect the pressure intensity and behavior is important and captures the interest of many researchers. Mostly, these forces are obeying to the direct impact of the gate geometries as well as the nearby flow conditions.

Among the basic objectives of studying the distribution of pressure at various points along the gate bottom is to know the flow pattern below the gate and to associate it with the fluctuating pressure on the gate bottom. Thus, the indication of the separation and reattachment points along the gate lip is useful in the present investigation due to their importance in describing the behavior of the flow beneath the gate, hence detecting whether the separated flow from the leading edge of the gate lip will reattach or remain separated from the gate bottom. The zone of separation can be distinguished by visual observation, and it can also be pointed as a region of low constant piezometric head followed by a sudden pressure rise [1].

Relevant independent variables that affect the bottom pressure coefficients can be arranged in the following functional relationship between the significant parameters [1]:

$K_{\mathrm{b}}=f\left(\frac{e}{d}, \frac{r}{d}, \frac{y}{d}, \frac{X}{d}, H_{i}, H_{\mathrm{d}}, V_{\mathrm{j}}\right)$.

The bottom pressure coefficient $\left(K_{\mathrm{b}}\right)$ can be calculated using the following expression:

$K_{\mathrm{b}}=\frac{H_{i}-H_{\mathrm{d}}}{V_{\mathrm{j}}^{2} / 2 g}$

where $\left(H_{i}\right)$ is the local piezometric head on the bottom gate surface which is measured through ten piezometric holes which are equivalent to fifteen as shown in Fig. 2. The measurements were taken with the gate held stationary under free and submerged flow conditions.

The variation in bottom pressure coefficient $\left(K_{\mathrm{b}}\right)$ along the gate bottom is displayed as non-dimensional plots versus $(x / d)$ for different gate openings and various gate lip shapes in Figs. 3, 4, 5, 6, 7, 8, and 9. The values $\left(K_{\mathrm{b}}\right)$ in these figures are obtained from the $\left(H_{i}\right)$ measurements in the piezometric holes which are located at $5 \mathrm{~cm}$ from the

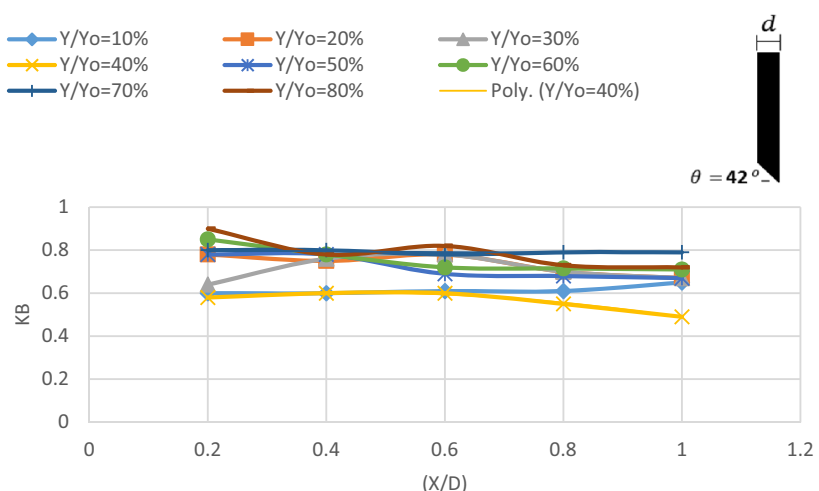

Fig. 3 Variation of $\left(K_{\mathrm{b}}\right)$ along the gate bottom surface for $\left(\theta=42^{\circ}\right)$ and different gate openings

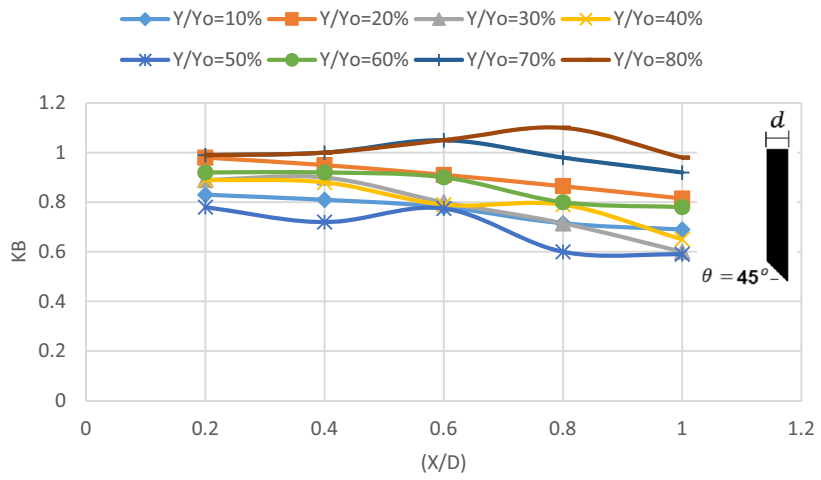

Fig. 4 Variation of $\left(K_{b}\right)$ along the gate bottom surface for $\left(\theta=45^{\circ}\right)$ and different gate openings

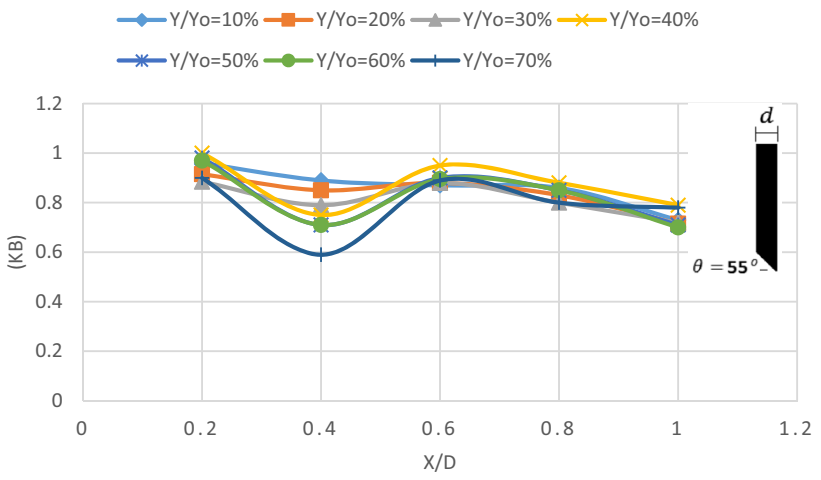

Fig. 5 Variation of $\left(K_{\mathrm{b}}\right)$ along the gate bottom surface for $\left(\theta=55^{\circ}\right)$ and different gate openings

edge of the gate lip. The distance $\mathrm{x}$ is measured horizontally from the leading edge of the gate lip toward its trailing edge.

$\left(K_{\mathrm{b}}\right)$ values for $\left(Y / Y_{o}=10 \%\right)$ mostly represent free flow conditions, and consequently, increasing the size of gate openings leads to change the flow conditions to be completely immersed and pressurized. 


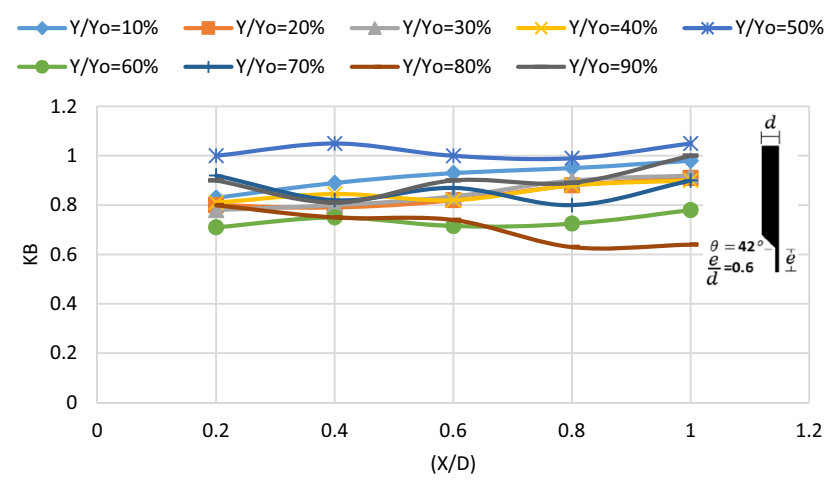

Fig. 6 Variation of $\left(K_{\mathrm{b}}\right)$ along the gate bottom surface for $\left(\theta=42^{\circ} \mathrm{el}\right.$ $d=0.6)$ and different gate openings

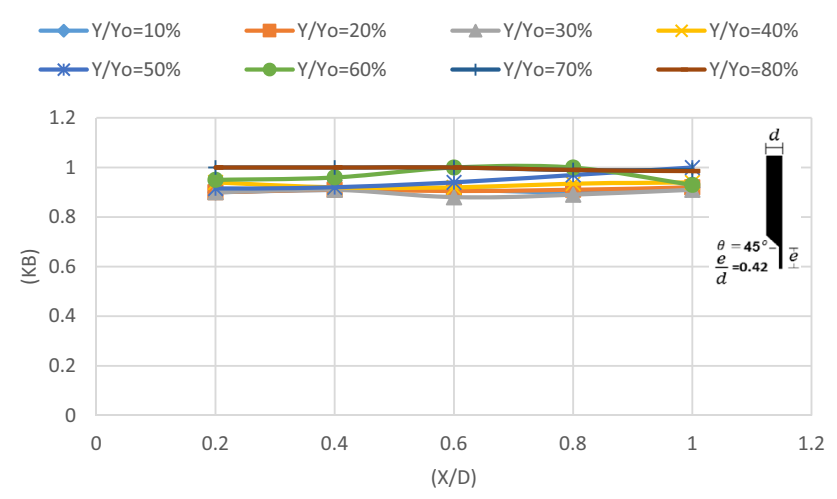

Fig. 7 Variation of $\left(K_{\mathrm{b}}\right)$ along the gate bottom surface for $\left(\theta=45^{\circ} \mathrm{el}\right.$ $d=0.42$ ) and different gate openings

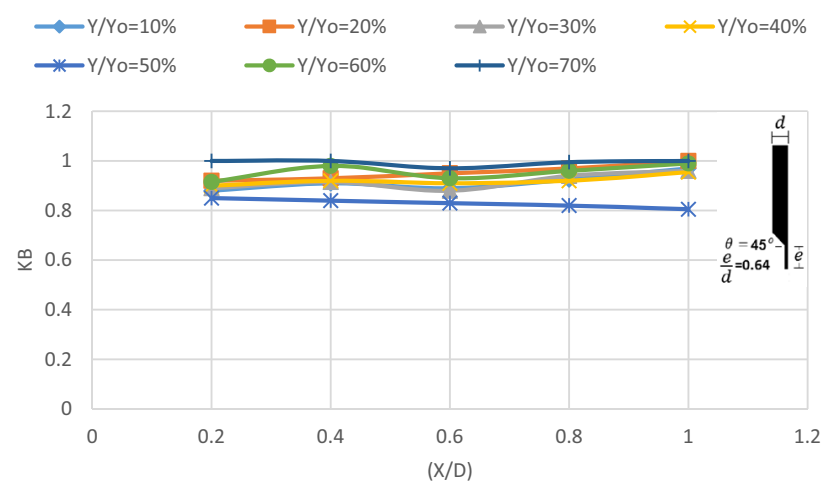

Fig. 8 Variation of $\left(K_{\mathrm{b}}\right)$ along the gate bottom surface for $\left(\theta=45^{\circ} \mathrm{e}\right.$ $d=0.64)$ and different gate openings

\section{Distribution of Bottom Pressure Coefficient $\left(K_{b}\right)$ Along Gate Lip Without Extension}

As mentioned earlier, the current study included testing of different forms of gates with and without extension. Figures from 3, 4, and 5 show the change in the pressure coefficient along the bottom surface of different gate shapes without extensions.

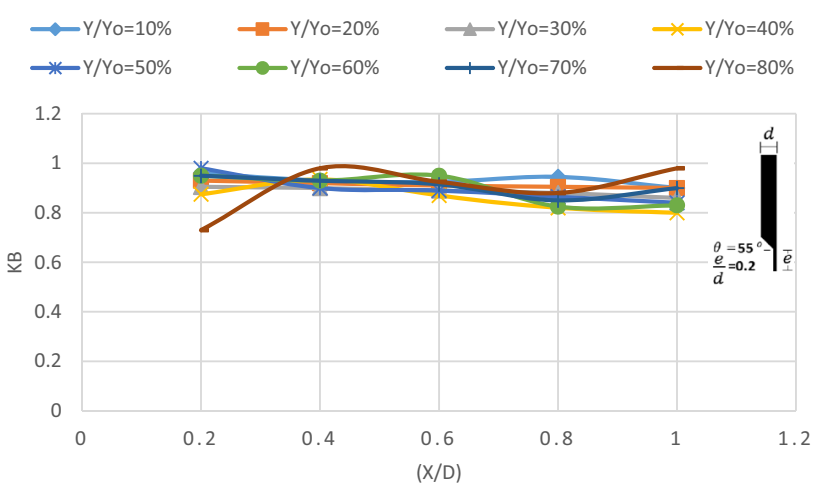

Fig. 9 Variation of $\left(K_{\mathrm{b}}\right)$ along the gate bottom surface for $\left(\theta=55^{\circ} \mathrm{el}\right.$ $d=0.2$ ) and different gate openings

Figure 3 indicates that, for $\left(Y / Y_{o}=20 \%, 30 \%\right.$, and $40 \%$ ), the flow is attached to the gate bottom surface from the leading edge up to $(x / d=0.668)$ with different intensity impacts and then followed by flow separation which extended toward the trailing edge. For other gate openings, except $\left(Y / Y_{o}=80 \%\right)$, the flow is attached to the gate bottom surface at the leading up to $(x / d=0.4)$ with $\left(K_{\mathrm{b}}\right)$ values between ( 0.8 and 0.9$)$ which then decreased to about (0.7) with smooth variation toward the trailing edge. For $\left(Y / Y_{o}=80 \%\right)$, it can be observed that the pressure coefficient line alternates from an attachment to reattachment states to a distance of $(x / d)$ up to $(0.8)$ and then continues with regular pressure values up to the end of the gate.

Figure 4 indicates that, for gate lip shape with $\left(\theta=45^{\circ}\right)$ and $\left(Y / Y_{o}=10 \%, 20 \% 30 \%, 40 \%, 50 \%\right.$, and $\left.60 \%\right)$, the flow is attached to the bottom surface of the gate from its leading edge up to $(x / d=0.4)$; then, it is followed by slight instabilities up to the trailing edge. For large gate openings $\left(Y / Y_{o}=80 \%\right)$, the attachment continues to a point $(x /$ $d=0.71)$. These results indicate that the tendency of flow toward separation may be reduced by adopting such geometries. Furthermore, as a result of the high values of $\left(K_{\mathrm{b}}=0.7\right.$ and 1.0), and its being positive along the entire lip, the downpull force on the gate may be kept to a minimum resulting in reduced gate hoisting capacity. However, the figure shows that all values of $\left(K_{\mathrm{b}}\right)$ are positive and decrease, with smooth variation, toward the trailing edge.

Figure 5 shows the $\left(K_{\mathrm{b}}\right)$ distribution for sloping gate lips of $\left(\theta=55^{\circ}\right)$. It can be observed from this figure that for all values of gate opening ratios $\left(Y / Y_{o}\right)$, the flow is attached to the leading edge and then moves away until the most severe separation which is established at $(x / d=40 \%)$, after which, it reattaches at $(x / d=60 \%)$, and then followed by a regular drop of the bottom pressure coefficient $\left(K_{\mathrm{b}}\right)$ values toward the trailing edge of gate. It can also be seen that for $\left(Y / Y_{o}=10 \%\right)$ which represents the free flow condition and $\left(Y / Y_{o}=20 \%\right)$, the $\left(K_{\mathrm{b}}\right)$ values are high and vary smoothly 
along the bottom edge. This indicates the probability of some degrees of vibration reflected on the stability of the gate and its mechanical system.

The comparison between the inclined gate lips of $\left(\theta=42^{\circ}, 45^{\circ}\right.$, and $\left.55^{\circ}\right)$ as to their effects on the values of $\left(K_{\mathrm{b}}\right)$, and hence on the downpull force, shows that $\left(K_{\mathrm{b}}\right)$ values for gate lip shape $\left(\theta=42^{\circ}\right)$ are less and ranged between $(0.6$ and 0.8$)$, whereas for gate lip shapes with $\left(\theta=45^{\circ}\right.$ and $\left.\theta=55^{\circ}\right)$ are higher and the values mainly fall between (0.8) and (1.0), and this means that their effect will be more pronounced in reducing the values of the hydraulic forces if the effect of the downward forces is considered to be uniform approaching the state of stability.

Similar work by using only the cases of ordinary gate lips of $\left(\theta=45^{\circ}\right.$ and $\left.\theta=55^{\circ}\right)$ has been conducted by Taher [11]. Their results showed that $K_{\mathrm{b}}$ values are relatively between 0.25 and 0.45 at low $Y / Y_{o}$, and then all were reduced and converge to lower values as $Y / Y_{\mathrm{o}}$ increases. These results are clearly different from those obtained from the current study which already based upon a constant flow rate of $\left(Q=0.035 \mathrm{~m}^{3} / \mathrm{s}\right)$, which has a significant effect on behavior and values of $\left(K_{\mathrm{b}}\right)$, and this value is mostly different from that used by Taher [11]. Such difference in results of $K_{\mathrm{b}}$ seems possible and expected and may be attributed to their different experimental conditions. Accordingly, comparison is always needed and should be made for similar conditions.

\section{Distribution of Bottom Pressure Coefficient $\left(K_{b}\right)$ Along Gate Lip with Extension}

Figures $6,7,8,9$, and 10 present the results of measurements on inclined gate lips of $\left(\theta=42^{\circ}, 45^{\circ}\right.$, and $\left.55^{\circ}\right)$ with different extensions which have been provided at the trailing edge and their effects on the distribution of $\left(K_{\mathrm{b}}\right)$ values along the gate bottom. It can be seen from these figures that the lip extension provides a stabilizing influence on distribution of $\left(K_{\mathrm{b}}\right)$ along the gate bottom. $\left(K_{\mathrm{b}}\right)$ values are constant or vary smoothly, with values generally falling between (0.8 and 1.0). A departure from this general trend has been occurred at very large gate openings. The value of gate opening $(Y)$ in the case of gate with lip extension is taken as a distance measured from the lower edge of the extension to the tunnel floor. Figure 6 with $\left(\theta=42^{\circ}, e / d=0.6\right)$ shows that for $\left(Y / Y_{o}=10 \%, 20 \%\right.$, $30 \%, 40 \%$, and $50 \%)$, the $\left(K_{\mathrm{b}}\right)$ values are increased uniformly toward the trailing edge, while the large gate openings $\left(Y / Y_{o} \geq 60 \%\right)$ have produced a fluctuation that clearly shows the phenomenon of flow attachment and separation. However, the extension seems to have less effect for large gate openings, and the effect of lip extension appears to be less for large gate openings.
Figure 7 shows a uniform $\left(K_{\mathrm{b}}\right)$ distribution along gate bottom of $\left(\theta=45^{\circ} \mathrm{e} / \mathrm{d}=0.42\right)$ for all gate openings which refers to a state of stability and may most likely lead to the absence of any effective separation. It is also seen from this figure that the values of $\left(K_{\mathrm{b}}\right)$ are high and may lead to reduce the downpull force to very low or even negative values.

Figures 8 and 9 reveal some interesting and informative results regarding the variation of $\left(K_{\mathrm{b}}\right)$ values on the gate bottom with various gate openings. Figure 8 with $\left(\theta=45^{\circ}\right.$, $e / d=0.6)$ indicates that for all gate openings, the $\left(K_{\mathrm{b}}\right)$ distribution is approximately constant with slight changes along bottom gate surface and the values are relatively high and fall between ( 0.9 and 1$)$ which also caused reduction in values of downpull force. Accordingly, no significant separation can be noticed and, to some extent, the gate may have a good degree of stability.

Figure 9 with $\left(\theta=55^{\circ} \mathrm{e} / \mathrm{d}=0.2\right)$ reveals that $\left(K_{\mathrm{b}}\right)$ has the same smooth distributions for all gate openings except $\left(Y / Y_{o}=80 \%\right.$ and $\left.90 \%\right)$, and the values are decreased with a little bit changes toward the trailing edge and flow separation starts from $(x / d=0.40$.) and continues up to trailing edge of gate. The $\left(K_{\mathrm{b}}\right)$ values ranged from 0.9 to 1.0 . The figure also indicates that for large openings $\left(Y / Y_{o}=80 \%\right.$ and $90 \%$ ) the gate being subjected to variation in bottom pressure accompanied by the occurrence of the state of separation and reattachment. The separation can be visually indicated by low values of pressure, and consequently, such case can be observed clearly beyond $(x / d=0.5)$ up to $(x / d=0.7)$.

\section{Comparison of the Effect of Different Lip Extension Ratios on Bottom Pressure Coefficient}

The present study included an assessment of the effect of adding the lip extension to the trailing edge of the gate on the bottom pressure coefficients $\left(K_{\mathrm{b}}\right)$. The main objective behind adding variable proportions of the extensions to the trailing edge of the gate is to study their effect on increasing the bottom pressure values inducing below the gate. Accordingly, the probability of exposing the gate to the negative impact of downpull forces can be reduced, hence avoiding any damage that may result from it. In addition, it is necessary to determine whether the distribution of pressure after adding the extension will be more systematic and helps to reduce the possibility of fluctuations and vibrations that could threaten the stability of the gate and the performance of mechanical system.

Figures 10, 11, and 12 show a comparison of the values and distribution of $\left(K_{\mathrm{b}}\right)$ for specific gate lip angles with and without lip extension against various gate openings $\left(Y / Y_{o}\right)$. It can be seen from Fig. 10 that for gate openings up to 


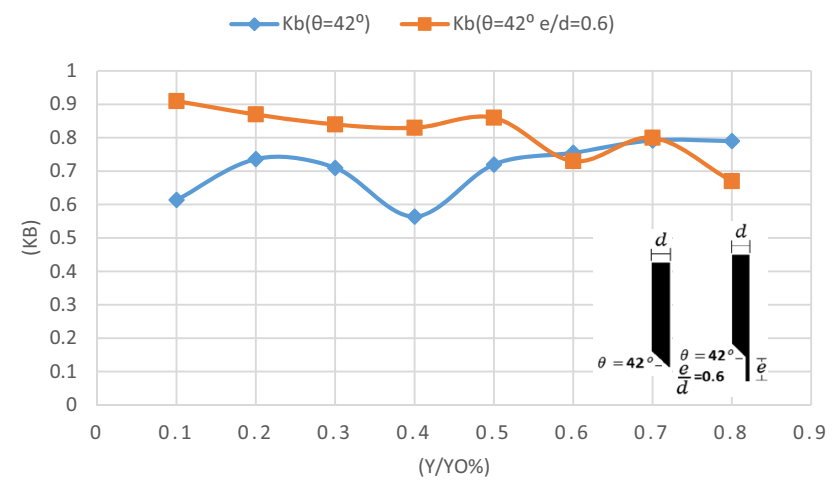

Fig. 10 Comparison of $\left(K_{\mathrm{b}}\right)$ for $\left(\theta=42^{\circ}\right)$ and $\left(\theta=42^{\circ}\right.$ eld $\left.=0.6\right)$ and different gate openings

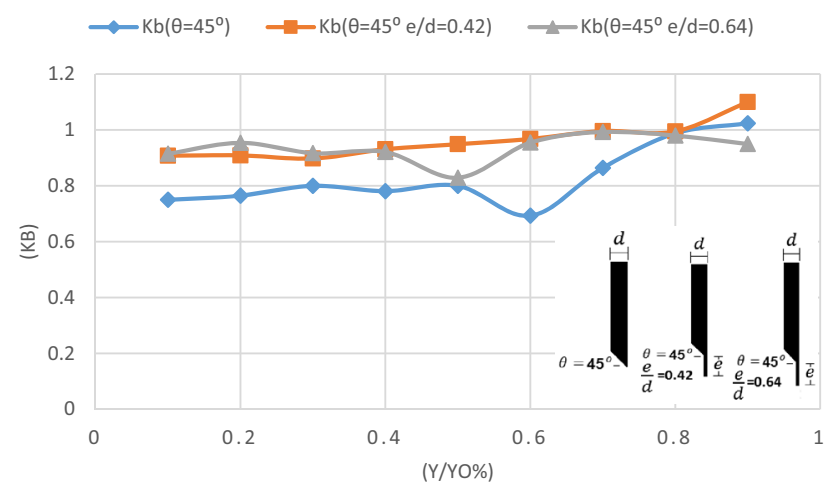

Fig. 11 Comparison of $\left(K_{\mathrm{b}}\right)$ for $\left(\theta=45^{\circ}\right)$ and $\left(\theta=45^{\circ}\right.$ eld $\left.=0.42\right)$ and different gate openings

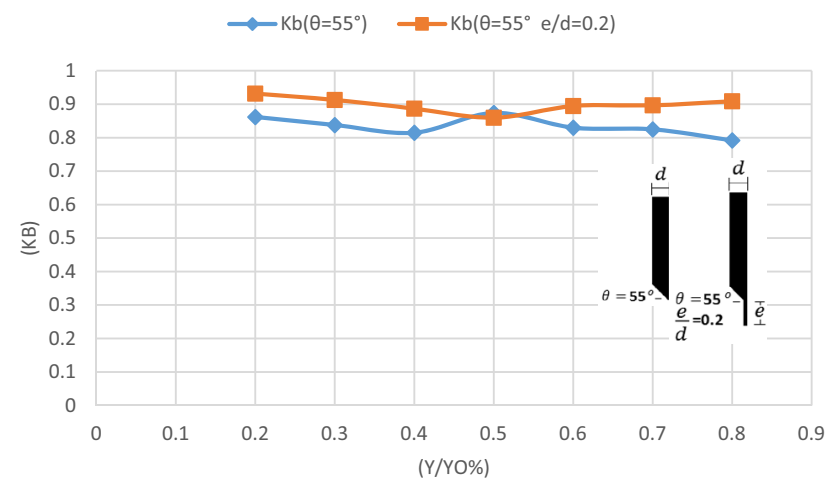

Fig. 12 Comparison of $\left(K_{\mathrm{b}}\right)$ for $\left(\theta=55^{\circ}\right)$ and $\left(\theta=55^{\circ}\right.$ eld $\left.=0.2\right)$ and different gate openings

(50\%), the bottom pressure coefficient $\left(K_{\mathrm{b}}\right)$ for gate lip shape $\left(\theta=42^{\circ}\right.$ eld $\left.=0.6\right)$ is increased and being more by $(30 \% \mathrm{t})$ than those obtained for gate lip shapes of $\left(\theta=42^{\circ}\right)$ without extension and then dropped smoothly as gate openings increased. For large openings, the values and distribution of bottom pressure resulting from the use of these two gate shapes seem to be close and less discrepancy is observed.
Figure 11 shows that the use of gate lip shapes $\left(\theta=45^{\circ}\right.$ $e / d=0.42$ and $\theta=45^{\circ}$ eld $=0.64$ ) caused an increase in $\left(K_{\mathrm{b}}\right)$ for about $(25 \%)$ over that without lip extension and produces uniform distribution with gate openings up to $(Y /$ $Y_{o}=80 \%$ ), beyond which no significant effect is noticed for these shapes when compared with the gate lip shape of $\left(\theta=45^{\circ}\right)$.

As it can be observed from Fig. 12 that for gate lip shape of $\left(\theta=55^{\circ}\right.$ eld $\left.=0.2\right)$, the $\left(K_{\mathrm{b}}\right)$ is approximately constant with higher values for about $(10 \%)$ than those indicated from gate lip shape of $\left(\theta=45^{\circ}\right)$.

\section{Statistical Analysis}

As mentioned earlier, a statistical program was used to find Pearson's correlation coefficient between the pressure distribution points at the bottom of the gate to indicate whether the distribution curve behaves uniformly or involves fluctuation. Although this coefficient of correlation depends on the linear relationship and may does not match the case of nonlinear pressure distribution under the gate, the use of this coefficient is still useful as an indicator for the existence of a state of separation and reattachment. The high correlation coefficient values give clear indications regarding the general order of the pressure distribution uniformity which in turn put some light on the absence or limited impact of the case of separation and reattachment along the bottom of the gate which can support the analysis of the results of experimental measurements to an acceptable degree of accuracy.

Table 1 shows the results of correlation coefficients which have been obtained from the using of Statistical Package of Social Sciences (SPSS). The results indicated that for the most large gate openings, the low values of correlation coefficients are dominated and represent the probability of fluctuation occurrence; hence, the gate may be subjected to many challenges due to vibration. The table also shows that for lip gate shape of $\left(\theta=45^{\circ} \mathrm{e}\right.$ $d=0.42$ ), the correlation coefficients clarify that the irregularity of the pressure distribution curve takes place in the openings $\left(Y / Y_{o}=20 \%, 40 \%, 50 \%\right.$, and $\left.70 \%\right)$ and reflects a relative difference from the other gate lip shapes.

\section{Maximum Bottom Pressure Coefficients}

By studying the pressure distributions for various gate shapes and openings as shown in Figs. 3, 4, 5, 6, 7, 8, and 9 , as well as studying the statistical tables which include different correlation coefficients in their values, it is found that there is no possibility to develop a general equation for estimating pressure conditions on the bottom of the gate. It 
Table 1 Pearson's correlation of $\left(K_{\mathrm{b}}\right)$ or various lip gate shapes

\begin{tabular}{|c|c|c|c|c|c|c|c|c|c|c|}
\hline Lip gate shapes & $Y / Y_{o} \%$ & $10 \%$ & $20 \%$ & $30 \%$ & $40 \%$ & $50 \%$ & $60 \%$ & $70 \%$ & $80 \%$ & $90 \%$ \\
\hline \multirow[t]{2}{*}{$\theta=42^{\circ}$} & $R^{2}$ & -.737 & $-.985^{* *}$ & $-.972 * *$ & -.794 & $-.941^{*}$ & -.852 & -.753 & .612 & \\
\hline & Sig. & & .076 & .058 & 1.000 & .113 & .029 & .034 & .319 & \\
\hline \multirow[t]{2}{*}{$\theta=45^{\circ}$} & $R^{2}$ & $-.981 * *$ & $-.996^{* *}$ & $-.960 * *$ & $-.935^{*}$ & -.854 & $-.925^{*}$ & -.543 & .251 & $-.981 * *$ \\
\hline & Sig. & & .003 & .000 & .010 & .020 & .065 & .025 & .344 & .683 \\
\hline \multirow[t]{2}{*}{$\theta=55^{\circ}$} & $R^{2}$ & & $-.928 *$ & -.875 & -.734 & -.437 & -.532 & -.537 & -.038 & \\
\hline & Sig. & & .023 & .052 & .158 & .462 & .356 & .350 & .952 & \\
\hline \multirow[t]{2}{*}{$\theta=42^{\circ}$ eld $=0.6$} & $R^{2}$ & & $.979 * *$ & $.935^{*}$ & $.982 * *$ & $.884 *$ & .214 & .626 & -.185 & $-.941 *$ \\
\hline & Sig. & & .004 & .020 & .003 & .047 & .729 & .258 & .765 & .017 \\
\hline \multirow[t]{2}{*}{$\theta=45^{\circ}$ eld $=0.42$} & $R^{2}$ & & .567 & .853 & .000 & .231 & $.972 * *$ & .000 & -.866 & $-.894 *$ \\
\hline & Sig. & & .319 & .066 & 1.000 & .708 & .006 & 1.000 & .058 & .041 \\
\hline \multirow[t]{2}{*}{$\theta=45^{\circ}$ eld $=0.6$} & $R^{2}$ & & .872 & $.985 * *$ & .780 & .839 & $-.996^{* *}$ & .642 & -.061 & \\
\hline & Sig. & & .054 & .002 & .120 & .076 & .000 & .243 & .923 & \\
\hline \multirow[t]{2}{*}{$\theta=55^{\circ}$ eld $=0.2$} & $R^{2}$ & & -.737 & $-.985 * *$ & $-.972 * *$ & -.794 & $-.941^{*}$ & -.852 & -.753 & .612 \\
\hline & Sig. & & .155 & .002 & .006 & .109 & .017 & .067 & .142 & .273 \\
\hline
\end{tabular}

**Correlation is significant at the 0.01 level (2-tailed)

*Correlation is significant at the 0.05 level (2-tailed)

Table 2 The values and positions of highest of $\left(K_{\mathrm{b}}\right)$ for various lip gate shapes

\begin{tabular}{|c|c|c|c|c|c|c|c|c|c|}
\hline Lip gate shape & $Y / Y_{o}$ & $10 \%$ & $20 \%$ & $30 \%$ & $40 \%$ & $50 \%$ & $60 \%$ & $70 \%$ & $80 \%$ \\
\hline \multirow[t]{2}{*}{$\theta=42^{\circ}$} & $K_{\mathrm{b}} \max$ & 0.65 & 0.78 & 0.78 & 0.6 & 0.78 & 0.85 & 0.8 & 0.9 \\
\hline & $x / d$ & 1.0 & $0.2,0.6$ & 0.6 & $0.4,0.6$ & $0.2,0.4$ & 0.2 & $0.2,0.4$ & 0.2 \\
\hline \multirow[t]{2}{*}{$\theta=45^{\circ}$} & $K_{\mathrm{b}} \max$ & 0.83 & 0.98 & 0.9 & 0.89 & 0.78 & 0.92 & 1050 & 1.1 \\
\hline & $x / d$ & 0.2 & 0.2 & 0.4 & 0.2 & 0.2 & $0.2,0.4$ & 0.6 & 0.8 \\
\hline \multirow[t]{2}{*}{$\theta=55^{\circ}$} & $K_{\mathrm{b}} \max$ & - & 0.96 & 0.915 & 0.88 & 1.0 & 0.98 & 0.97 & 0.9 \\
\hline & $x / d$ & 0.2 & 0.2 & 0.2 & 0.2 & 0.2 & 0.2 & 0.2 & 0.2 \\
\hline \multirow[t]{2}{*}{$\theta=42^{\circ}$ eld $=0.6$} & $K_{\mathrm{b}} \max$ & 0.98 & 0.91 & 0.92 & 0.9 & 1.050 & 0.78 & 0.92 & 0.8 \\
\hline & $x / d$ & 1.0 & 1.0 & 1.0 & 1.0 & 1.0 & 0.2 & 1,0 & 1.0 \\
\hline \multirow[t]{2}{*}{$\theta=45^{\circ}$ eld $=0.42$} & $K_{\mathrm{b}} \max$ & - & 0.92 & 0.92 & 0.91 & 0.94 & 1.0 & 1.0 & 1.0 \\
\hline & $x / d$ & 1.0 & 1.0 & 1.0 & $0.2,1.0$ & 1.0 & $0.6,0.8$ & $0.2,0.4,0.6$ & $0.2,0.4,0.6$ \\
\hline \multirow[t]{2}{*}{$\theta=45^{\circ}$ eld $=0.6$} & $K_{\mathrm{b}} \max$ & - & 0.97 & 1.0 & 0.96 & 0.955 & 0.85 & 0.99 & 1.0 \\
\hline & $x / d$ & - & 1.0 & 1.0 & 1.0 & 1.0 & 0.2 & 1.0 & $0.2,0.4,1.0$ \\
\hline \multirow[t]{2}{*}{$\theta=55^{\circ}$ eld $=0.2$} & $K_{\mathrm{b}} \max$ & 0.96 & 0.93 & 0.905 & 0.935 & 0.98 & 0.95 & 0.95 & 0.98 \\
\hline & $x / d$ & 0.2 & 0.2 & 0.2 & 0.4 & 0.2 & $0.2,0.6$ & 0.2 & $0.4,1.0$ \\
\hline
\end{tabular}

is therefore useful to determine the highest bottom pressure values for various gate lip shapes and openings with their corresponding positions which can serve as design determinants as it can be seen through Table 2 .

\section{Conclusions}

In the current study, the bottom pressure coefficients $\left(K_{\mathrm{b}}\right)$ were estimated by using the results of experimental work for various inclined gate lip shapes (with and without lip extension) and different gate openings. The study is based upon the constant values of flow rate and gap shaft ratios.
The behavior of flow stream lines below the gates as a function to the variation of bottom pressure coefficient was analyzed and used to identify the separation zones and hence their effects on stability of the gate.

An attempt was used to analyze the results of bottom pressure coefficients $\left(K_{\mathrm{b}}\right)$ by using the Pearson's correlation coefficients of Statistical Package of Social Sciences (SPSS) as indicator for the pressure uniformity or nonuniformity below the gate and thus for gate stability. Moreover, the highest values of $\left(K_{\mathrm{b}}\right)$ are listed in specific table and suggested to be design determinants.

Some of the major conclusions are listed as follows: 
1. For gate openings up to $(50 \%)$ of bottom gate surface of $\left(\theta=42^{\circ}\right)$, the flow is attached to the bottom gate surface up to $(x / d=0.6)$ which then slightly separates toward the trailing edge. It is also found that as gate openings increased, the separation may occur earlier.

2. For most gate openings of gate lip shape of $\left(\theta=45^{\circ}\right)$, the flow is attached to the bottom surface of the gate from its leading edge up to $(x / d=0.4)$; then, it is followed by slight instabilities up to the trailing edge.

3. For gate lip shape of $\left(\theta=55^{\circ}\right)$, a significant fluctuation was observed in values and pattern of flow which is mostly concentrated at $(x / d=0.35)$. A high intensity of this attachment and reattachment phenomenon may threat the stability of gate and create troubles for its operation performance. It may be recommended to avoid using this gate lip shape.

4. The comparison between the inclined gate lips $\left(\theta=42^{\circ}, 45^{\circ}\right.$, and $\left.55^{\circ}\right)$ with respect to their effects on the values of $\left(K_{\mathrm{b}}\right)$ and therefore on the downpull indicates that the $\left(K_{\mathrm{b}}\right)$ values of $\left(\theta=42^{\circ}\right)$ are the lowest and ranged as ( 0.6 up to 0.8$)$, whereas the gate lip shapes of $\left(\theta=45^{\circ}\right.$ and $\left.\theta=55^{\circ}\right)$ produced higher $\left(K_{\mathrm{b}}\right)$ values which in turn lead to reduce the downpull force especially when top pressure coefficient considered as invariant.

5. For gate openings $\left(Y / Y_{o}=10 \%, 20 \%, 30 \%, 40 \%\right.$, and $50 \%$ ), the use of gate lip shapes with different ratios of extensions such as $\left(\theta=42^{\circ}\right.$, e/d $=0.6, \theta=45^{\circ} \mathrm{el}$ $d=0.42$, and $\theta=45^{\circ}$, eld $=0.6$ ) shows an increase in the $\left(K_{\mathrm{b}}\right)$ values and decrease in the degree of fluctuations to acceptable extent when compared with results from other shapes without extension, while at large gate openings $\left(Y / Y_{o} \geq 60 \%\right)$ a fluctuation was clear that verified the phenomenon of flow attachment and separation. However, the effect of lip extension appears to be less for large gate openings.

6. For all gate openings of $\left(\theta=45^{\circ} e / d=0.42\right)$, a state of pressure stability was seen and may most likely lead to the absence of any effective separation. It is also seen from that the values of $\left(K_{\mathrm{b}}\right)$ are high and may lead to reduce the downpull force to very low or even negative values.

7. For all gate openings of $\left(\theta=45^{\circ}\right.$, eld $\left.=0.6\right)$, except $\left(Y / Y_{o}=60 \%\right)$, the $\left(K_{\mathrm{b}}\right)$ distribution varied uniformly with slight changes along bottom gate surface and the values are relatively high and fall between ( 0.9 and 1$)$ which also caused reduction in values of downpull force. Accordingly, no significant separation can be noticed, and for some extent, the gate may have a good degree of stability.
8. For the case of $\left(\theta=55^{\circ} e / d=0.2\right)$, the $\left(K_{\mathrm{b}}\right)$ has the same smooth distributions for all gate openings except $\left(Y / Y_{o}=80 \%\right.$ and $\left.90 \%\right)$, the values are decreased with little changes toward the trailing edge, and flow separation starts from $(x / d=0.40$.) and continues up to trailing edge of gate. The $\left(K_{\mathrm{b}}\right)$ values ranged from (0.9 to 1.0.). For large openings $\left(Y / Y_{o}=80 \%\right.$ and $\left.90 \%\right)$, the gate is shown subjected to variation in bottom pressure accompanied by the occurrence of the state of separation and reattachment. The separation can be visually indicated by low values of pressure, and consequently, such case can be observed clearly beyond $(x / d=0.5)$ up to $(x /$ $d=0.7)$.

9. For gate openings up to $(50 \%)$, the bottom pressure coefficients $\left(K_{\mathrm{b}}\right)$ for gate lip shape $\left(\theta=42^{\circ} \mathrm{e}\right.$ $d=0.6)$ are greater by $(30 \%)$ more than those obtained for gate lip shapes of $\left(\theta=42^{\circ}\right)$ and then dropped smoothly as gate openings increased. For large openings, the values and distribution of bottom pressure resulting from the use of these two gate shapes are seemed to be close and less discrepancy is observed.

10. Using of shapes $\left(\theta=45^{\circ}\right.$ eld $=0.42$ and $\theta=45^{\circ}$ el $d=0.64)$ resulted in uniform distribution for $\left(K_{\mathrm{b}}\right)$ and led to increase its values $(25 \%)$ in comparison with the gate lip shape of $\left(\theta=45^{\circ}\right)$.

11. For shape $\left(\theta=55^{\circ} e / d=0.2\right)$, the $\left(K_{\mathrm{b}}\right)$ is varied uniformly with higher values for about $(10 \%)$ than those indicated from gate lip shape of $\left(\theta=55^{\circ}\right)$.

12. Fluctuation occurrence is confirmed by applying SPSS. In general, the gates may be subjected to vibrations which play role in pressure non-uniform distribution.

\section{References}

1. T.M. Ahmed, Effects of gate lip shapes on the downpull force in tunnel gates. Thesis Presented to the Baghdad University in Partial Fulfillment of the Requirements for Degree of Doctor of Philosophy in Hydraulic Engineering, 1999

2. B.T. AL-Kadi, Numerical evaluation of downpull force in tunnel gates. Ph.D Thesis submitted to the College of Engineering, University of Baghdad, 1997

3. V.P. Bhargava, S. Narasimhan, Pressure fluctuations on gates. J. Hydraul. Res. 27(2), 215-231 (1989)

4. R.A. Elder, J.M. Garrison, Form-induced hydraulic forces on three leaf intake gates. J. Hydraul. Div. 90(HY3), 215-233 (1964)

5. E. Naudaschers, H.E. Kobus, R.P.R. Rao, Hydrodynamic analysis for high-head leaf gates. J. Hydraul. Div. ASCE 90(HY3), 155-192 (1964)

6. N.D. Thang, E. Naudascher, Approach flow effect on downpull of gates. ASCE 109(11), 1521-1539 (1983) 
7. Nguyen D. Thang, Gate vibrations due to unstable flow separation. J. Hydraul. Eng. 116(3), 342-361 (1990)

8. B.T.A. Sagar, Downpull in high-head gate installations, parts 1, 2, 3. Water Power Dam Construct 3, 38-39; 4, 52-55; 5, 29-35 (1977)

9. B.T.A. Sagar, J.P. Tullis, Prediction of gate shaft pressure in tunnel gate. Water Power Dam Construct 12, 35-41 (1979)

10. Peter M. Smith, Hydraulic downpull on ICE harbor power gate. ASCE 90(HY3), 193-213 (1964)
11. T.M. Taher, A.O. Anwar, Effects of gate lip orientation on bottom pressure coefficient of dam tunnel gate. Arab. J. Sci. Eng. 41, 4927-4936 (2016)

12. US Bureau of Reclamation and Army Engineers. Hydraulic downpull force on large gates, Research Report No. 4 (1966)

Publisher's Note Springer Nature remains neutral with regard to jurisdictional claims in published maps and institutional affiliations. 